University of Nebraska - Lincoln

DigitalCommons@University of Nebraska - Lincoln

USDA National Wildlife Research Center - Staff Publications
U.S. Department of Agriculture: Animal and Plant Health Inspection Service

2019

\title{
Road hogs: Implications from GPS collared feral swine in pastureland habitat on the general utility of road-based observation techniques for assessing abundance
}

\author{
Raoul K. Boughton \\ University of Florida \\ Benjamin L. Allen \\ University of Southern Queensland \\ Eric A. Tillman \\ University of Florida \\ Samantha M. Wisely \\ University of Florida \\ Richard M. Engeman \\ NWRC, s_r100@yahoo.com
}

Follow this and additional works at: https://digitalcommons.unl.edu/icwdm_usdanwrc

Part of the Life Sciences Commons

Boughton, Raoul K.; Allen, Benjamin L.; Tillman, Eric A.; Wisely, Samantha M.; and Engeman, Richard M., "Road hogs: Implications from GPS collared feral swine in pastureland habitat on the general utility of road-based observation techniques for assessing abundance" (2019). USDA National Wildlife Research Center - Staff Publications. 2226.

https://digitalcommons.unl.edu/icwdm_usdanwrc/2226

This Article is brought to you for free and open access by the U.S. Department of Agriculture: Animal and Plant Health Inspection Service at DigitalCommons@University of Nebraska - Lincoln. It has been accepted for inclusion in USDA National Wildlife Research Center - Staff Publications by an authorized administrator of DigitalCommons@University of Nebraska - Lincoln. 
Original Articles

\title{
Road hogs: Implications from GPS collared feral swine in pastureland habitat on the general utility of road-based observation techniques for assessing abundance
}

\author{
Raoul K. Boughton ${ }^{\mathrm{a}}$, Benjamin L. Allen ${ }^{\mathrm{b}}$, Eric A. Tillman ${ }^{\mathrm{c}}$, Samantha M. Wisely ${ }^{\mathrm{d}}$, \\ Richard M. Engeman ${ }^{\mathrm{e}, *}$ \\ ${ }^{a}$ Department of Wildlife, Ecology and Conservation, University of Florida - IFAS, Range Cattle Research and Education Center, 3401 Experiment Station, Ona, FL 33865, \\ USA \\ ${ }^{\mathrm{b}}$ University of Southern Queensland, Institute for Agriculture and the Environment, Toowoomba, Queensland 4350, Australia \\ ${ }^{\mathrm{c}}$ National Wildlife Research Center, USDA/APHIS/WS, Florida Field Station, 2820 E University Blvd, Gainesville, FL 32641, USA \\ ${ }^{\mathrm{d}}$ Department of Wildlife Ecology and Conservation, University of Florida, 110 Newins-Ziegler Hall, Gainesville, FL 32611-0430, USA \\ ${ }^{\mathrm{e}}$ National Wildlife Research Center, 4101 LaPorte Avenue, Fort Collins, CO 80521-2154, USA
}

\section{A R T I C L E I N F O}

\section{Keywords:}

Camera trap

Feral pig

Invasive species

Population index

Population monitoring

Sus scrofa

Tracking plot

\begin{abstract}
A B S T R A C T
Feral swine are among the world's most destructive invasive species, and monitoring their populations is essential for research and management purposes. Observation stations located along primitive roads have been an efficient and effective means to intercept the daily activities of many animal species for collecting data from which abundance indices can be validly calculated. Feral swine are among the many species documented to use primitive (dirt), low-use roads as routes to easily traverse surrounding habitats and thus be well-monitored in various habitats globally by using road-based observation stations such as camera traps or tracking plots. However, there are relatively few assessments of this approach's general utility. Here, we examine whether roadbased observations would be useful in pastureland habitat where roads would be expected to minimally benefit swine as travel pathways. Using GPS collars, we monitored movements of 18 adult feral swine ( 9 male, 9 female) in a south-central Florida pastureland habitat. We found 17 of 18 swine (94\%) were located on roads over half of the days they were monitored. In fact, the average for our sample of swine was road locations on $77 \%$ of days they were monitored. Moreover, for days when our monitored swine were located on roads, they averaged 5.3 road crossings/day. For just our combined sample of 18 feral swine, 76 road locations would be expected each day. We concluded that although pastureland habitat offers minimal resistance to overland travel, feral swine are still frequently found on roads, making road-based observation systems likely to be an efficient means to collect population monitoring data in this easily traversed habitat, in addition to those habitats where overland travel would be more challenging to swine. This implies a very general utility for a road-based observation system for collecting data from which indices of abundance may be calculated for feral swine.
\end{abstract}

\section{Introduction}

Feral swine (Sus scrofa) are among the world's most destructive invasive species, and their inclusion is well-deserved as one of the 100 "World's Worst" invaders by the IUCN Invasive Species Specialist Group (e.g. Lowe et al., 2004). This species, which has the greatest reproductive potential of all large wild mammals in North America, and possibly the world (Bieber and Ruf, 2005; West et al., 2009), is infamous worldwide for damaging native plant species, animal species, and habitats, as well as archaeological sites (Choquenot et al., 1996;
Engeman et al., 2007, 2013, 2017; Seward et al., 2004; Singer et al., 1981; USDA, 1999, 2016; USDA/APHIS, 2015). They also harbor diseases transmittable to wildlife, livestock, or humans (e.g., Corn et al., 2005; USDA/APHIS, 2015; USDA, 2016; Wyckoff et al., 2009). The crucial need to manage feral swine populations is likewise accompanied by a fundamental need to monitor their population abundance, for both research and management applications, and as embodied by the old adage "If you can't monitor it, you can't manage it" (Engeman et al., 2013). A reliably applicable and practical data gathering approach for producing an index of feral swine population abundance that is suitable

\footnotetext{
* Corresponding author.

E-mail address: richard.m.engeman@aphis.usda.gov (R.M. Engeman).
} 
for a broad variety of habitats would be a valuable asset.

Efficiencies in obtaining data for calculating population abundance indices are often possible because rarely do animals operate in a spatially random pattern. For example, food availability, cover, and avoidance of predators may act to influence patterns of movement, as well as energy conservation and ease of movement across the landscape (e.g., Allen et al., 2014a,b; Bider, 1968; Elledge, 2011; Evangelista et al., 2009; McCallum, 2000; Whittington et al., 2005). Many species around the world preferentially use the path of least resistance for travel, which in many areas includes low-use dirt roads or tracks. Thus, road-based observation methods for assessing abundance, such as camera traps and tracking plots, can take advantage of this behavioral characteristic and have been used to efficiently intercept animal activity for a variety of population indexing procedures for many species in many places globally (e.g., Allen et al., 2013; Allen and Engeman, 1995; Bider, 1968; Catling and Burt, 1995; Elledge, 2011; Engeman, 2005; Engeman et al., 2002; Jiang et al., 2006; Long et al., 2008; Olifiers et al., 2011). If such travel ways are distributed throughout the area of interest, they can provide a means for observation that is an efficient and representative sampling of the local population, and the resulting data can be used to provide an index of abundance for the population inhabiting the geographical area (Engeman, 2005; Engeman et al., 2013, 2017). In environments that are difficult to traverse, roads can be obvious paths of least resistance for movement through those landscapes for both wildlife and humans, thereby making road-based observation stations an efficient strategy for collecting data using methods like tracking plots or camera stations. However, a road-based observation strategy may not be advantageous in terrains that offer little resistance to movement, and perhaps provide little incentive for wildlife to use roads (Evangelista et al., 2009; Mahon et al., 1998). Obtaining information on whether or not a given species would use roads through easy-to-traverse terrains would be valuable for choosing and validating a sampling method (Allen and Engeman, 2015).

Available information from indexing populations of wild canids reinforces the view that it is wise to assess whether road-based observations will intercept the routine activities of a species. Canids around the world have often been particularly well-monitored using road-based observations, especially tracking plots (e.g., Allen et al., 2014a,b; Andelt and Andelt, 1984; Engeman and Allen, 2000; Engeman et al., 2000). However, when Evangelista et al. (2009) applied tracking plots to obtain population indexing data for Ethiopian wolves (Canis simensis) in a habitat with vegetation often only a few $\mathrm{cm}$ high, they found roads offered no benefits over adjacent terrain as travel pathways. Thus, road-based tracking stations did not efficiently intercept the animals' activity. It is therefore prudent to consider how the species of interest is using the matrix of habitat that surrounds the road system when considering road-based surveys.

Feral swine are among the many species that have been well-monitored using road-based observation stations in certain difficult-to-traverse off-road habitats around the world (Allen and Engeman, 1995; Elledge, 2011; Engeman et al., 2001, 2002; Jiang et al., 2006; Theuerkauf and Rouys, 2008). For example, in south Texas Engeman et al. (2002) demonstrated that data collection from tracking stations on dirt roads was greatly superior to data collection from tracking stations on off-road bare patches situated in vegetation communities dominated by dense stands of shrubs, primarily honey mesquite (Prosopis glandulosa), blackbush acacia (Acacia rigidula), sweet acacia ( $A$. minuta) and pricklypear (Opuntia spp.) (Fig. 1). Other off-road habitats referenced above included tropical rainforest (Elledge, 2011), wetland/ saw palmetto (Engeman et al., 2001), temperate forests (Jiang et al., 2006; Theuerkauf and Rouys, 2008), and arid Australian outback (Allen and Engeman, 1995). In each of these landscapes, roads were advantageous for animal movement and were efficient for intercepting the swine activity.

The utility of road-based observations for producing an indicator/ index of a species' abundance improves with the species' propensity to use roads. Similar to the road-based tracking station tests for Ethiopian wolves, we wanted to test whether road-based observation stations would intercept feral swine activity when the surrounding habitat offered minimal resistance for travel. To do so, we considered whether feral swine in open grassland dominated habitats (pasturelands) would use roads as routes of travel. We used GPS tracking collars to investigate the frequency and timing of swine movement across roads in pasturelands in south-central Florida. Compared to natural habitats in the region, pasturelands offer little resistance for travel by feral swine, and we discuss our results in light of implications for assessing feral swine populations using road-based index observations. Our primary aim in this study was to answer the question "Is it reasonable to use road-based observation stations to collect data for indexing the feral swine population in a habitat (pastureland) that presents minimal challenge for travel through the landscape?" If the answer to this question is "yes," then the implication would be that it is reasonable to use road-based observation stations for feral swine in nearly all habitats traversed by primitive or other little-used roads.

\section{Methods}

\subsection{Site description}

We conducted this research at the MacArthur Agro-Ecology Research Center (MAERC) of Buck Island Ranch, a 4170-ha commercial cattle ranch $\sim 30 \mathrm{~km}$ northwest of Lake Okeechobee, Florida (see detailed description by Boughton and Boughton, 2014). Although feral swine were first known to be introduced to Florida by Hernando de Soto in 1539 (Towne and Wentworth, 1950), it is unknown when feral swine were first observed in the study area. Records of their presence exist from homesteads of the nearby Kissimmee River Valley as early as 1840 where free range domestic swine were ranched (Mayer and Brisbin, 2008). Feral swine have been abundant on the property for many years, as evidenced by $200-400$ feral swine having been trapped or hunted annually from 2007 to 2012 (Boughton and Boughton, 2014).

The area's subtropical climate exhibits distinct wet (May-Oct.) and dry (Nov-Apr) seasons, with annual rainfall averaging ca $1300 \mathrm{~mm}$. The average mid-summer temperature is $26^{\circ} \mathrm{C}$ (July), and the average midwinter temperature is $13^{\circ} \mathrm{C}$ (January). The study area is characterized by grassland habitats, with 1638 ha of semi-native pastures of $\mathrm{C} 4$ native perennial grasses including native bunchgrasses (e.g., Andropogon virginicus, Panicum longifolium, and Axonopus fissifolius). These semi-native pastures are representative of wet prairie habitat and have never been fertilized or plowed. Improved grasslands were established over time on the dryer, higher sections of the ranch which now also includes 1521 ha of sown pastures, mainly Bahia grass (Paspalum notatum). The study site is dotted with 627 seasonal wetlands amounting to 541 ha embedded within the grasslands, as well as several oak and palm hammocks (276 ha) and just over $800 \mathrm{~km}$ of drainage ditches (Boughton and Boughton, 2014). Similar to most ranches in the region, the grasslands at Buck Island Ranch are subjected to prescribed burns every 2-3 years in the winter to manage for forage and suppress woody plants. Primitive road/vehicle tracks are found through all portions of the property (Fig. 2-A).

\subsection{Capture and handling}

From 4 to 9 January 2013, feral swine were trapped for outfitting with GPS collars. Feral swine were captured using 16 pen traps, $244 \mathrm{~cm} \times 122 \mathrm{~cm} \times 152 \mathrm{~cm}(\mathrm{~L} \times \mathrm{W} \times \mathrm{H})$, with drop doors. Traps were pre-baited for two weeks with soured corn and then set in the evening and checked each morning. Over 71 trap nights, 26 boars, 31 sows and 42 juvenile/piglets were captured. Once a trap had caught a sow and boar of appropriate size for fitting with a collar, that trap site was no longer used to insure an even geographical distribution of feral swine in our sample, and to also avoid having swine from the same group in our 

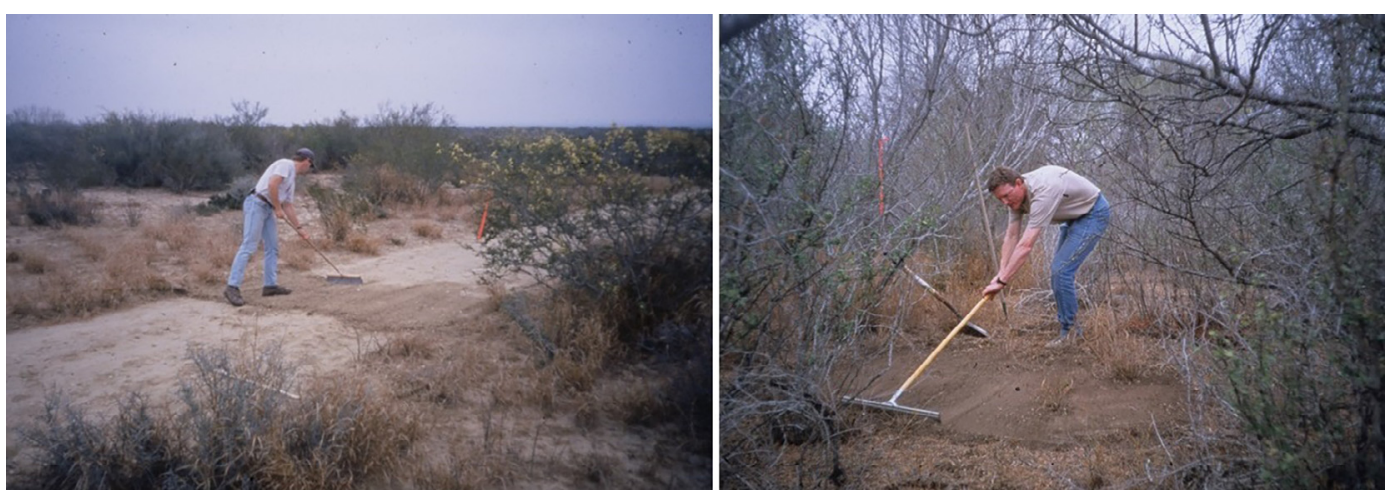

Fig. 1. The photo on the left shows the preparation of a tracking plot of a dirt road in rural south Texas, while the photo on the right shows preparation of a tracking plot in the off-road habitat in the same area, which is dominated by thick stands of (prickly) shrubs. (Engeman et al., 2002). Photos by R. Engeman.

sample. Captured swine were tranquilized using a mixture of Telazol ${ }^{\circledast}$ and xylazine (Gabor et al., 1997), with temperature monitored and ophthalmic ointment applied during GPS collar attachment. There were 10 adult males and 10 adult females fitted with GPS collars. The Archbold Biological Station IACUC, \#ABS-AUP-011-R, approved all animal capture and handling procedures.

\subsection{GPS collar data collection}

Trapped feral swine were outfitted with Lotek 3300 GPS collars. By insuring that our captured study animals were geographically distributed throughout the study area, we were attempting to avoid obtaining data from one animal that would essentially duplicate data obtained from a companion animal. The collars automatically dropped off the animals beginning May 10, 2013 and were located using VHF receivers from May 10, 2013 through to May 25, 2013. We programmed collars to collect location fixes every $15 \mathrm{~min}$ from 18:00 pm until 6:45 am and then every two hours starting at 8:00 am finishing at 18:00 pm (i.e., 18:00 pm can be considered the final daily $2 \mathrm{~h}$ gap reading or the first $15 \mathrm{~min}$ gap reading). Collection of points was restricted to these times to coincide with prime feral swine activity periods, and to conserve battery power.

\subsection{GIS analyses}

To address our objectives, we had to first define when swine were
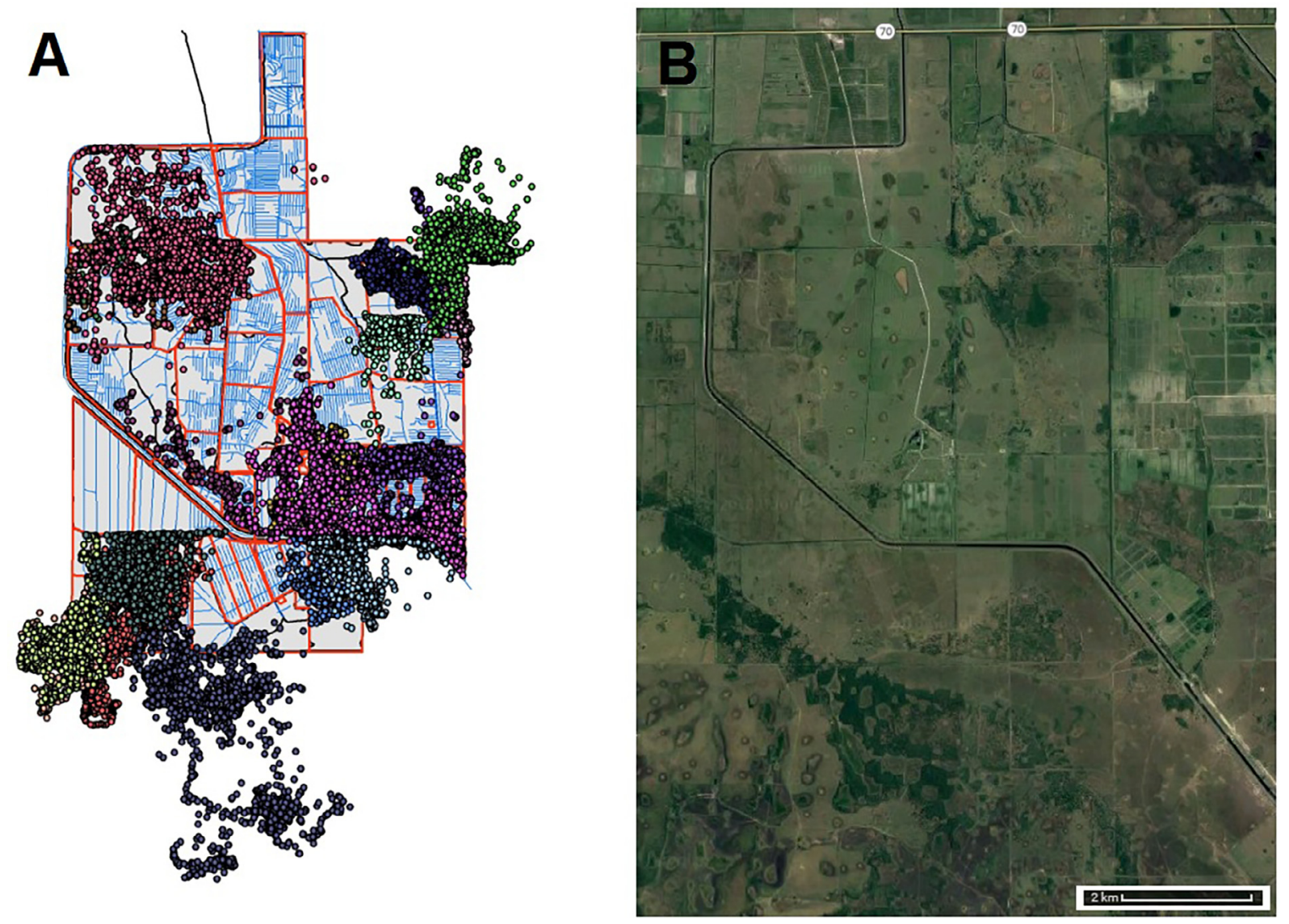

Fig. 2. A: A map showing the primitive roads (thicker lines) through the study area at the MacArthur Agro-Ecology Research Center (MAERC) of Buck Island Ranch in south-central Florida (thin lines are ditches). The small circles show the GPS locations for 18 feral swine outfitted with GPS collars, January to May 2013. B: An aerial view of the study area illustrating the homogeneity of its pastureland habitat. 
Table 1

Road usage of 9 male and 9 female feral swine fitted with GPS collars at the MacArthur Agro-Ecology Research Center (MAERC) of Buck Island Ranch in south-central Florida, January to May 2013.

\begin{tabular}{llll}
\hline Swine ID & $\begin{array}{l}\text { \% GPS points } \\
\text { representing road } \\
\text { crossings (N points) }\end{array}$ & $\begin{array}{l}\text { \% days with road } \\
\text { crossings (N days } \\
\text { tracked) }\end{array}$ & $\begin{array}{l}\text { Mean \# crossings } \\
\text { on days when on } \\
\text { roads }\end{array}$ \\
\hline 004-F & $5.24 \%(2997)$ & $50.94 \%(53)$ & 5.81 \\
$025-\mathrm{F}$ & $6.05 \%(3818)$ & $69.41 \%(85)$ & 3.92 \\
$034-\mathrm{F}$ & $2.28 \%(703)$ & $43.75 \%(16)$ & 2.29 \\
$055-\mathrm{F}$ & $5.76 \%(4586)$ & $51.16 \%(86)$ & 6.00 \\
$065-\mathrm{M}$ & $5.22 \%(4755)$ & $70.93 \%(86)$ & 4.07 \\
$074-\mathrm{F}$ & $6.62 \%(4338)$ & $67.44 \%(86)$ & 4.95 \\
$105-\mathrm{M}$ & $8.30 \%(4689)$ & $94.19 \%(86)$ & 4.80 \\
$115-\mathrm{F}$ & $17.25 \%(4677)$ & $100.00 \%(86)$ & 9.38 \\
$125-\mathrm{F}$ & $4.26 \%(3006)$ & $62.26 \%(53)$ & 3.88 \\
$135-\mathrm{F}$ & $4.49 \%(3385)$ & $64.47 \%(76)$ & 3.10 \\
$155-\mathrm{M}$ & $6.47 \%(4375)$ & $74.42 \%(86)$ & 4.42 \\
$165-\mathrm{M}$ & $9.50 \%(4589)$ & $89.53 \%(86)$ & 5.66 \\
$195-\mathrm{M}$ & $10.41 \%(951)$ & $53.52 \%(71)$ & 2.61 \\
$206-\mathrm{F}$ & $17.36 \%(4354)$ & $98.84 \%(86)$ & 8.89 \\
$215-\mathrm{M}$ & $16.06 \%(4471)$ & $97.67 \%(86)$ & 8.55 \\
$225-\mathrm{M}$ & $12.80 \%(4195)$ & $96.51 \%(86)$ & 6.47 \\
$235-\mathrm{M}$ & $4.39 \%(3962)$ & $60.47 \%(86)$ & 3.35 \\
$245-\mathrm{M}$ & $13.01 \%(4641)$ & $100.00 \%(86)$ & 7.02 \\
\hline Totals & $9.18 \%(68492)$ & $77.49 \%(1386)$ & 5.29 \\
\hline
\end{tabular}

on roads, given the nature of GPS collar data collected at $15 \mathrm{~min}$ intervals. Ideally, data would be analog, which would essentially result in a video showing if feral swine movements followed road features. However, because our GPS collar data were collected at $15 \mathrm{~min}$ intervals, we could not know the paths of the animals between the time points. The most certain way of knowing whether a swine was on a road was if two consecutive GPS locations were on opposite sides of a road. The amount of road usage in those intervening $15 \mathrm{~min}$. could have ranged from a swine just crossing the road to a swine following the road for the full $15 \mathrm{~min}$ before veering off the other side. A series of GPS fixes that crossed roads multiple times would be a strong indication of swine spending considerable time on the road (i.e., 3 consecutive fixes alternating sides of a road would indicate up to a half hour on the road). Clearly, using road crossings as a representation or indicator of road use is a conservative approach. It cannot take into account swine that enter a road, perhaps travel down it, but do not cross it. Also, $15 \mathrm{~min}$. on a road might be considered an extended time for a mobile animal, meaning that a swine could enter a road, travel it, even cross it and cross back in between location fixes, and therefore not be identified by our data as having crossed a road.

Swine movements were assessed in ArcView v9.3 and v10.2 (ESRI Inc.) using the extensions XToolsPro v7.0 (Data East LLC) and Hawths Tools v3. Animal point data (GPS locations) were first converted to lines (approximate movement paths), then, after obtaining vector datasets on the locations of the study site's landscape features including roads, fences, ditches, canals (Fig. 2), we plotted swine movements in chronological order and identified movement lines that crossed or followed roads. Thus, for our analyses we used the frequency of location fixes on opposite sides of roads per day as a quantitative indicator of that individual's road activity/usage for that day.

Positional accuracy of GPS points was assessed using the Horizontal Dilution of Precision (HDOP) values (range 1-25) recorded with each GPS point, with a lower value indicating a higher probability of a more accurate GPS location. Mean HDOP values ranged between 2.35 and 2.97, and fixed collar tests at the study site indicated that HDOP values of 5 or less represented $<50 \mathrm{~m}$ on-ground error for $99 \%$ of fixes (R. Boughton, unpublished data). Given that over $97 \%$ of acquired GPS points $(\mathrm{N}=68,492)$ had an associated HDOP value of 5 or less, we considered all data suitable for inclusion in all analyses and none were excluded based on HDOP values.

\subsection{Metrics indicating road usage}

Given our approach to defining feral swine usage of roads from GPS collar data, we also needed to define metrics to quantify their usage of roads in terms helpful for inferring whether or not road-based observation stations would be a reasonable monitoring strategy. Our first consideration was that if roads are a suitable means for passively intercepting daily feral swine activity and making observations, then we felt from experience that it would be beneficial for individual feral swine to be on roads most days. Thus, we examined the percentage of the days that each animal was monitored that also included locations on a road. As an additional metric, increasing activity conducted by a swine on roads would be reflected in an increasing number of road crossings for each day that it was on roads. For our purposes using roadbased observation stations, we would want nearly all swine to be on roads most days (e.g., each swine is on roads over half of the days monitored) and on those days typically show multiple fixes across roads to imply usage rather than random crossing of roads (e.g., multiple road crossings per day on average for days when roads were used).

We also were interested in consistency across animals in road usage, which we evaluated by examining how similar road activity through the day was among individual animals. Also, if road crossings for feral swine were a reflection of their activity levels, then through the course of the hours of a day the road activity would relate directly with activity levels. Thus, for each animal we grouped their accumulated road crossings and plotted them according to hour of the day. We then correlated the hourly values between all possible pairs of animals (153 possible pairwise combinations) to compare individual activity times among all animals.

\section{Results}

No collars were lost from study animals, but technical problems with some GPS collars resulted in data from only 18 animals ( 9 male and 9 female) of the 20 collared being available for analyses. While GPS locations showed geographical overlap among some of our collared animals (Fig. 2-A), the timing of the locations resulted in minimal time spent with other collared animals, which was not surprising given that our trapping strategy aimed to insure our monitored swine were distributed through the 4170-ha study area and thus from different social groups. These 18 swine were monitored for a mean of 77 days (range 16-86), and each collar recorded 703-4755 (mean = 3805) GPS points during this time (Table 1). Of the 18 feral swine with GPS collars, 17 (94\%) were on roads at least $50 \%$ of the days in which they were monitored. The one exception (034-F) was on roads 7 of the 16 days (44\%) it was monitored. However, the 16 days this individual was monitored was by far the fewest days of monitoring among all individuals. All other swine had at least 53 days of monitoring, and moreover, 13 of the 18 (72\%) collared swine were monitored $\geq 85$ days (Table 1). Of the 18 collared animals, 7 (39\%) were on roads $90-100 \%$ of days monitored, while 14 of the 18 collared swine (78\%) were on roads at least $60 \%$ of the days during which they were monitored (Table 1). Averaged across all collared individuals, the mean percent of days during which swine crossed roads was $77 \%$ (SE 4.63\%, N = 18) of days, or equivalently, 5-6 days per week.

On those days when feral swine were found on roads, the average number of crossings per day across all individuals was 5.3 per day. We cannot know exactly where feral swine were between GPS locations, making the true amounts of time actually spent on roads unknown, and the number of observed crossings a minimum (conservative) representation of road usage. The precise location of crossings was also unknown, because between two observations from either side of the road it could not be determined where in that $15 \mathrm{~min}$, span that the swine actually crossed the road. Nevertheless, road crossings appeared random and not associated with a particular landscape features in this fairly homogenous habitat (Fig. 2-B). Multiple crossings per day 

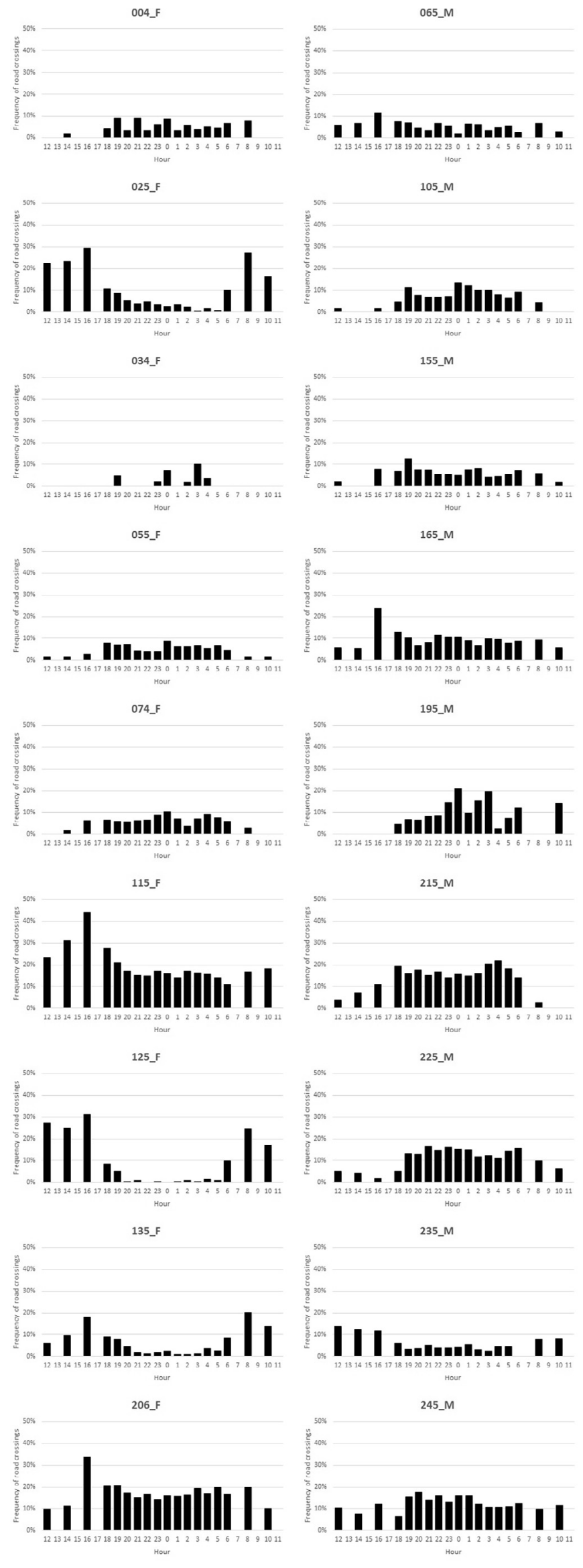

Fig. 3. The frequency at which roads were crossed through the hours of the day for each of 18 feral swine fitted with GPS collars at the MacArthur Agro-Ecology Research Center (MAERC) of Buck Island Ranch in south-central Florida.

illustrate the potential for observation stations along roads to "capture" an observation on an individual animal. Animal 034-F, as would be expected from above, had the lowest average number of daily crossings (2.3/day) on days it was observed to be on roads (Table 1 ). In contrast, $115-\mathrm{F}$ crossed roads every day of our study, averaging 9.4 crossings per day. For each animal, we can calculate the expected number of times it would cross roads on any given day by multiplying the probability that it would use roads on any given day (proportion of days it crossed roads) with the average number of road crossings on those days where it crossed roads. Thus, the expected number of daily crossings for 034-F would be $0.44 \times 2.3=1.0$ expected road crossings per day. The expected number of daily crossings for 115 -F would be $1.0 \times 9.4$ for 9.4 expected crossings per day. The expected road crossings for each animal are given in Table 1. From a group perspective, the expected number of daily road crossings for our sample is the sum of the individual expected road crossings, which for just these 18 feral swine is 76 expected daily crossings (Table 1).

Monitored swine used roads primarily at night (Fig. 3), as expected, because extensive previous research has shown feral swine to be more active during nocturnal hours than during the day (e.g., Caley, 1997; Franckowiak et al., 2018; Saunders and Kay, 1991; Singer et al., 1981). All the same, we were more curious to see how well activity, relative to road crossing times, conformed among the individual feral swine. Of the 153 pairwise correlations for road crossings across time of day among the 18 feral swine, $49(32 \%)$ were not detectably different from zero (i.e., p > 0.10). Just three feral swine accounted for $74 \%$ (32) of these lower correlations, implying the temporal activity patterns for these three feral swine were generally unrelated to the activity patterns of the other feral swine. In particular, individual $135 \mathrm{~F}$ had 15 of its 17 correlations with other feral swine not detectably different from zero (p > 0.10). On the other hand, 56 of the 153 correlations (37\%) indicated a high correspondence in road crossing activity with $r>0.80$. There were an additional 97 positive correlations found different from zero but of lesser magnitudes (0.41-0.79). Only 7 of the 31 negative correlations were found to be different from zero. These results indicate general similarities among most feral swine in their road crossing activity through the course of a day.

\section{Discussion}

The monitoring objective for wildlife populations is not to monitor the area of interest, but rather the population inhabiting that area. Thus, an index of relative abundance based on data gathered along primitive, low-use roads through the area often is an appropriate indicator of abundance and useful for monitoring population changes or trends (Engeman, 2005). Crucial to the quality of that index is an understanding of how roads are used by wildlife in a particular region (Allen and Engeman, 2015; Engeman, 2005). Although pastureland offers little resistance for cross-country travel compared with many other environments inhabited by feral swine, our results suggest that road-based observations offer an efficient means to make observations of swine, because swine crossed roads multiple times on most days in pastureland habitat. Our results further suggest that these road based methods offer a means to index and monitor changes in relative abundance for feral swine in most habitats in which they are found, if roads or tracks are distributed through the area of interest. A road density sufficient for assuring that all portions within the area of interest can be represented in data collection is an important consideration. Naturally, greater road density potentially allows for larger sample sizes of observation stations (and therefore improved precision) and also greater flexibility for placement of observation stations. 
Typically, the (primitive) dirt roads we described for placement of wildlife observation stations have little to no traffic each day, and the traffic that does occur in such rural settings is during daylight, while feral swine activity is mostly nocturnal. Yet, the road structure is available for travel by animals as well as vehicles. Roads that receive consistent traffic may not be suitable for placement of observation stations for two reasons. First, the traffic could obliterate data collection, especially for tracking plots. Second, large ungulates may be less likely to traverse roads with too much traffic (e.g., Alexander et al., 2005). For example, wild boar were observed to be deterred from major (paved) roads (Theuerkauf and Rouys, 2008), but few would consider busy roadways as sensible sites for making wildlife observations (except within wildlife passage ways under roads). Nevertheless, the propensity for feral swine (or other wildlife species) to be "captured" on a roadbased observation system would be inversely related to the amount of nighttime traffic. To our knowledge there have been no studies to define the amount of traffic (at night) that would deter (dirt/primitive) road usage by feral swine. Most reasonably, primitive roads likely wouldn't be primitive if they were needed to receive more than a very small amount of traffic, especially at night.

A key component for assessing the efficiency of an indicator/index for population abundance using road-based observation stations is to determine whether or not the daily activity patterns for the animals of interest includes roads (i.e., a path of least resistance) through a given habitat. However, if it is easy for animals to traverse surrounding habitats without using roads or tracks as a path of least resistance, then animals would use roads less frequently making a road-based observation system less efficient for monitoring animals through their normal daily activities. Thus, an evaluation of activity time and habitat use is essential for understanding the value of this monitoring system, as demonstrated by the few such studies in the literature (e.g., Allen et al., 2014b; Evangelista et al., 2009).

Here, we have shown that in a pastureland environment with minimal hindrances for travel, feral swine consistently used roads. Across all collared individuals, the swine averaged being on roads $77 \%$ of days. Additionally, 94\% (17 of 18) of our GPS-collared swine used roads on over half the days they were monitored. Not only were individual swine frequently on roads, they also averaged crossing roads 5.3 times per day on those days they were found on the roads, suggesting more than inconsequential road usage. With location fixes collected at $15 \mathrm{~min}$. intervals, 5.3 road crossings per day could range in time from 5 transits across roads to $1.25 \mathrm{~h}$ of time traveling on roads. Thus, ease of movement may be but one of multiple driving factors in road use by feral swine. The aspect of overriding importance for this study is that the swine were frequently on the roads, which in turn implies that roads are efficient locations for collecting data from which a population abundance indicator/index could be calculated and validly applied to monitor the population. A practitioner entering an area to monitor its feral swine population will be unlikely to have information on the behavior patterns or distribution of the animals in the area, yet a thorough (random) sampling of the road system for intrusions to observation stations is likely to obtain suitable data for indexing the population in most habitats.

Collection of population monitoring observations is typically conducted over multiple, usually consecutive days (e.g., Engeman, 2005), further implying that a road-based observation system for monitoring swine abundance should offer efficient and effective means to intercept feral swine movement activities for making observations in this habitat type. Still, when considering the initial implementation of a new monitoring approach or the application of an existing approach to a new habitat or other circumstances, it is prudent to first test the monitoring system under consideration (Allen and Engeman, 2015; Engeman, 2005). Many studies in difficult-to-traverse off-road habitats have found road-based observation stations to be efficient for collecting data for indexing feral swine population abundance (e.g., Allen and Engeman, 1995; Elledge, 2011; Engeman et al., 2001, 2002; Jiang et al.,
2006; Theuerkauf and Rouys, 2008). Even though the present study in pastureland habitat suggests a general utility for primitive road-based observation systems, it is advisable to test a road-based observation approach in a new area before committing to it for the long-term.

\section{Acknowledgements}

This research was supported by the intramural research program of the University of Florida; University of Southern Queensland; U.S. Department of Agriculture. We thank T. Campbell for assistance with GPS collar technologies and animal handling. This study was funded in part by a cooperative agreement from USDA APHIS WS National Wildlife Research Center (12-7412-0896-CA) to S. Wisely.

\section{Declarations of interest}

None.

\section{References}

Allen, B.L., Allen, L.R., Engeman, R.M., Leung, L.K.-P., 2013. Intraguild relationships between sympatric predators exposed to lethal control: an applied experimental test. Front. Zool. 10, 39.

Allen, B.L., Allen, L.R., Engeman, R.M., Leung, L.K.-P., 2014a. Sympatric prey responses to lethal top-predator control: predator manipulation experiments. Front. Zool. $11,56$.

Allen, L.R., Engeman, R.M., 1995. Assessing the impact of dingo predation on wildlife using an activity index. In: Proceedings of the 10th Australian Vertebrate Pest Conference. Hobart, Tasmania. pp. 72-79.

Allen, L.R., Engeman, R.M., 2015. Evaluating and validating abundance monitoring methods in absence of populations of known size. Environ. Sci. Pollut. Res. 22, 2907-2915.

Allen, B.L., Engeman, R.M., Leung, L.K.-P., 2014b. The short-term effects of a routine poisoning campaign on the movements and detectability of a social top-predator. Environ. Sci. Pollut. Res. 21, 2178-2190.

Andelt, W.F., Andelt, S.H., 1984. Diet bias in scat deposition rate surveys of coyote density. Wildlife Soc. Bull. 12, 74-77.

Alexander, S.M., Waters, N.M., Paquet, P.C., 2005. Traffic volume and highway permeability for a mammalian community in the Canadian Rocky Mountains. Can. Geogr. 49 (4), 321-331.

Bider, J.R., 1968. Animal activity in uncontrolled terrestrial communities as determined by a sand transect technique. Ecol. Monogr. 38, 1-306.

Bieber, C., Ruf, T., 2005. Population dynamics in wild boar Sus scrofa: ecology, elasticity of growth rate and implications for the management of pulsed resource consumers. J. Appl. Ecol. 42, 1203-1213.

Boughton, E.H., Boughton, R.K., 2014. Modification by an invasive ecosystem engineer shifts a wet prairie to a monotypic stand. Biol. Invasions 16, 2105-2114.

Caley, P., 1997. Movements, activity patterns and habitat use of feral pigs (Sus scrofa) in a tropical habitat. Wildlife Res. 24, 77-87.

Catling, P.C., Burt, R.J., 1995. Studies of the ground-dwelling mammals of eucalypt forests in south-eastern New South Wales: the effect of habitat variables on distribution and abundance. Wildlife Res. 22, 271-288.

Choquenot, D., McIlroy, J., Korn, T., 1996. Managing Vertebrate Pests: Feral Pigs. Bureau of Resource Sciences Australian Government Publishing Service, Canberra, ACT.

Corn, J.L., Cumbee, J.C., Chandler, B.A., Stallknecht, D.E., Fischer, J.R., 2005. Implication of feral swine expansion: expansion of feral swine in the United States and potential implication for domestic swine. In: Feral Swine Subcommittee on Brucellosis and Pseudorabies. United States Animal Health Association, St. Joseph, MO, pp. 295-297.

Elledge, A.E., 2011. Habitat preferences and environmental impacts of feral pigs (Sus scrofa) in lowland tropical rainforests of north-eastern Australia. Dissertation. University of Queensland, Brisbane, Australia.

Engeman, R.M., 2005. Indexing principles and a widely applicable paradigm for indexing animal populations. Wildlife Res. 32, 203-210.

Engeman, R.M., Allen, L.R., 2000. Overview of a passive tracking index for monitoring wild canids and associated species. Integr. Pest Manage. Rev. 5, 197-203.

Engeman, R.M., Allen, B.L., Allen, L.R., 2017. Study design concepts for inferring functional roles of mammalian top predators. Invited paper to special issue of Food Webs $12,56-63$.

Engeman, R.M., Constantin, B.U., Nelson, M., Woolard, J., Bourassa, J., 2001. Monitoring changes in feral swine population and spatial distribution of activity. Environ. Conserv. 28, 235-240.

Engeman, R.M., Massei, G., Sage, M., Gentle, M.N., 2013. Monitoring wild pig populations: a review of methods. Environ. Sci. Pollut. Res. 20, 8077-8091.

Engeman, R.M., Pipas, M.J., Gruver, K.S., Allen, L.R., 2000. Monitoring coyote populations with a passive activity index. Wildlife Res. 27, 553-557.

Engeman, R.M., Pipas, M.J., Gruver, K.S., Bourassa, J., Allen, L.R., 2002. Plot placement when using a passive tracking index to simultaneously monitor multiple species of animals. Wildlife Res. 29, 85-90.

Engeman, R.M., Stevens, A., Allen, J., Dunlap, J., Daniel, M., Teague, D., Constantin, B.U., 
2007. Feral swine management for conservation of an imperiled wetland habitat: Florida's vanishing seepage slopes. Biol. Conserv. 134, 440-446.

Evangelista, P., Engeman, R.M., Talents, L., 2009. Testing a passive tracking index for monitoring the endangered Ethiopian wolf populations on the Senetti Plateau, Ethiopia. Integr. Zool. 4, 172-178.

Franckowiak, G.A., Torres-Poché, Z., Poché, R.M., 2018. Activity patterns by feral hogs in the Texas panhandle. Am. Midl. Nat. 180, 233-245.

Gabor, T.M., Hellgren, E.C., Silvy, N.J., 1997. Immobilization of collared peccaries (Tayassu tajacu) and feral hogs (Sus scrofa) with Telazol ${ }^{\varpi}$ and xylazine. J. Wildlife Dis. 33, 161-164.

Jiang, G.S., Ma, J.Z., Zhang, M.H., 2006. Spatial distribution of ungulate responses to habitat factors in Wandashan forest region, northeastern China. J. Wildlife Manage. 70, 1470-1476.

Long, R.A., MacKay, P., Zielinski, W.J., Ray, J.C., 2008. Noninvasive Survey Methods for Carnivores. Island Press, Washington, D.C.

Lowe, S., Browne, M., Boudjelas, S., De Poorter, M., 2004. 100 of the World's Worst Invasive Alien Species A selection from the Global Invasive Species Database. Invasive Species Specialist Group, Auckland.

Mahon, P.S., Banks, P.B., Dickman, C.R., 1998. Population indices for wild carnivores: a critical study in sand-dune habitat, south-western Queensland. Wildlife Res. 25, $11-22$.

Mayer, J.J., Brisbin, I.L., 2008. Wild pigs in the United States: Their History, Comparative Morphology, and Current Status. The University of Georgia Press, Athens, GA.

McCallum, H., 2000. Population Parameters: Estimation for Ecological Models. Blackwell Science, Oxford.

Olifiers, N., Loretto, D., Rademaker, V., Cerqueira, R., 2011. Comparing the effectiveness of tracking methods for medium to large-sized mammals of Pantanal. Zoologia 28, 207-213.
Saunders, G., Kay, B., 1991. Movements of feral hogs (Sus scrofa) at Sunny Corner, New South Wales. Wildlife Res. 18, 49-61.

Seward, N., VerCauteren, K., Witmer, G., Engeman, R., 2004. Feral swine impacts on agriculture and the environment. Sheep Goat Res. J. 19, 34-40.

Singer, F.J., Otto, D.K., Tipton, A.R., Hable, C.P., 1981. Home ranges, movements, and habitat use of European wild boar in Tennessee. J. Wildlife Manage. 45, 343-453.

Theuerkauf, J., Rouys, S., 2008. Habitat selection by ungulates in relation to predation risk by wolves and humans in the Bialowieza Forest, Poland. Forest Ecol. Manage. 256, 1325-1332.

Towne, C.W., Wentworth, E.N., 1950. Pigs from Cave to Cornbelt. University of Oklahoma Press, Norman, Oklahoma.

USDA (U.S. Department of Agriculture), 1999. Wild pigs hidden danger for farmers and hunters., Animal and Plant Health Inspection Services Information Bulletin 620. Washington, D.C.

USDA (U.S. Department of Agriculture), 2016. Feral swine: damages, disease threats, and other risks. Animal and Plant Health Inspection Services Program Aid 2195b. Washington, D.C.

USDA/APHIS (U.S. Department of Agriculture/Animal and Plant Health Inspection Service), 2015. Final Environmental Impact Statement Feral Swine Damage Management: A National Approach. USDA/Animal and Plant Health Inspection Service. Washington, D.C.

West, B.C., Cooper, A.L., Armstrong, J.B., 2009. Managing wild pigs: a technical guide. Hum. Wildlife Interact. 1, 1-55.

Whittington, J., St. Clair, C.C., Mercer, G., 2005. Spatial responses of wolves to roads and trails in mountain valleys. Ecol. Appl. 15, 543-553.

Wyckoff, A.C., Henke, S.E., Campbell, T.A., Hewitt, D.G., VerCauteren, K.C., 2009. Feral swine contact with domestic swine: a serologic survey and assessment of potential for disease transmission. J. Wildlife Dis. 45, 422-429. 